\title{
Bone mineral density, vitamin D receptor (VDR) gene polymorphisms, fracture risk assessment (FRAX), and trabecular bone score (TBS) in rheumatoid arthritis patients: connecting pieces of the puzzle
}

\author{
Manar R. Senosi ${ }^{1} \cdot$ Hanan M. Fathi ${ }^{1} \cdot$ Noha M. Abdel Baki ${ }^{2} \cdot$ Othman Zaki ${ }^{3}$ Ahmed M. Magdy ${ }^{4}$ Tamer A. Gheita $^{2}$
}

Received: 1 December 2021 / Revised: 27 December 2021 / Accepted: 31 December 2021 / Published online: 19 January 2022

(c) International League of Associations for Rheumatology (ILAR) 2022

\begin{abstract}
Purpose To assess vitamin D receptor (VDR) gene polymorphisms and bone mineral density and to investigate the possible risk factors of osteoporosis and fracture in rheumatoid arthritis (RA).

Methods A total of 97 RA patients and 45 matched controls were enrolled. Serum vitamin D level, VDR genotyping, dualenergy X-ray absorptiometry (DEXA) scan, trabecular bone score (TBS), and fracture risk assessment (FRAX) in 10 years were assessed. Disease activity score (DAS28) and modified health assessment questionnaire (MHAQ) were measured.

Results The mean age of the patients was 47.9 \pm 8.9 years; 85 females, 12 males (F:M 7.1:1) and mean disease duration $9.4 \pm 6.2$ years. DAS 28 was $4.52 \pm 1.04$ and MHAQ $0.6 \pm 0.4$. There was a significant difference between cases and controls as regards DEXA and FRAX $(p<0.0001)$ but the TBS and VDR genotyping were comparable $(p=0.29$ and $p=0.12$, respectively). The vitamin D level was comparable with the control $(9.3 \pm 6.5 \mathrm{vs} 10.4 \pm 7.5 \mathrm{ng} / \mathrm{mL}, p=0.4)$. None of the patients was receiving anti-osteoporotic therapy or biologic therapy. There was a significant association between the presence of osteoporosis and age, disease duration, menopause, and rheumatoid factor (RF) positivity. The TBS was significantly lower and FRAX higher in patients with positive RF and anti-CCP. FRAX was significantly related and the TBS inversely with the age, disease duration, serum uric acid, alkaline phosphatase, and MHAQ.

Conclusions Reduced BMD and increased tendency to fractures are remarkable in RA patients. Vitamin D level was decreased in patients and control, and VDR gene polymorphisms were not linked to RA. TBS and FRAX are effective tools to assess osteoporotic fractures in RA.

Key Points

- Reduced bone mineral density (BMD) and increased tendency to fractures are remarkable in rheumatoid arthritis (RA) patients.

- Vitamin D level was decreased in patients and control, and VDR gene polymorphisms were not linked to RA.

- Trabecular bone score (TBS) and fracture risk assessment (FRAX) in 10 years are effective tools to assess osteoporotic fractures in RA.
\end{abstract}

Keywords Bone mineral density $\cdot$ DAS28 $\cdot$ FRAX $\cdot$ Rheumatoid arthritis $\cdot$ TBS $\cdot$ VDR

Tamer A. Gheita

gheitamer@hotmail.com

1 Rheumatology and Rehabilitation Department, Faculty of Medicine, Fayoum University, Fayoum, Egypt

2 Rheumatology and Clinical Immunology Department, Faculty of Medicine, Cairo University, Cairo, Egypt

3 Clinical Pathology Department, Faculty of Medicine, Damietta University, Damietta, Egypt

4 Radio-Diagnosis Department, Faculty of Medicine, Fayoum University, Fayoum, Egypt

\section{Introduction}

Rheumatoid arthritis (RA) is a chronic systemic autoimmune disease, with variable clinical expression. It arises more frequently in females than in males, being predominantly observed in the elderly. It can be ranging from mild self-limiting disorder to a very aggressive form, resulting in joint destruction and progressive disability [1]. Bone is a dynamic tissue that is continuously renewed throughout life by the process of bone remodeling. There is a disturbance in this equilibrium with increased resorption by osteoclasts and less bone formation by osteoblasts, leading bone to become weaker and more prone to fractures [2]. 
The remodeling process is the result of interactions between these cells (osteoclasts and osteoblasts) and multiple molecular agents, including growth factors, hormones, and cytokines [3]. Altered bone remodeling, whether excessive resorption and/or impaired formation, is a key risk for osteoporotic fracture $[4,5]$. The quality of life in RA patients has been markedly affected by osteoporosis and related fragility fractures, being one of the most common complications [6]. Multi-factorial conditions have been involved in RA development, but genetic factors are considered to be strong determinants of these conditions. One of these influencing genes in RA progress is the vitamin D receptor (VDR) gene and its polymorphisms [7]. There are several polymorphic sites in the $3^{\prime}$ region of the VDR human gene identified by restriction endonuclease enzymes TaqI, BsmI, ApaI, and another variant in the exon 2 recognized by FokI. These polymorphisms may affect the response to various dietary components with the potential raised risk for development of pathology, being demonstrated on a large scope by functional involvement of the alleles of the VDR on calcium homeostasis and bone mineralization [8].

The fracture risk assessment (FRAX) in 10 years tool was developed to evaluate the 10 -year risk of bone fragility fractures in females and males older than 40 years. This tool relies on selected clinical risk factors for fractures, where bone mineral density (BMD) was measured at the femoral neck. Adjusted versions were established, according to the local epidemiological data, and its availability for most countries in the world [9]. Osteoporosis is diagnosed using dual-energy X-ray absorptiometry (DXA) which measures BMD [10], but one of its limitations is its low value as an independent predictor of fracture risk [11, 12]. To overcome this limitation, the trabecular bone score (TBS) was developed to determine the bone's micro-architecture [13]. Thus, the objective of the current work was to assess VDR gene polymorphisms and BMD in Egyptian RA patients and to investigate the possible risk factors of osteoporosis and of fracture.

\section{Patients and methods}

The study included 97 RA patients fulfilling the American College of Rheumatology/European League Against Rheumatism (ACR/EULAR) classification criteria [14] and 45 age and sex matched healthy controls. Any patient with metabolic disorders, and/or secondary causes of osteoporosis as hyperthyroidism, premature menopause ( $<45$ years), chronic liver disease, or diabetes mellitus, was excluded. The patients' consents were obtained and the study was approved by the local ethics committee, in accordance with the 1964 Helsinki Declaration.
Patients were subjected to full history taking including menstrual and menopausal age, diet, sun exposure, smoking, current medications, prior fractures, family history of hip fracture as well as clinical examination, and assessment of the body mass index (BMI). Visual analog scale (VAS) - pain [15], modified health assessment questionnaire (MHAQ) [16], and disease activity score (DAS28) [17] were assessed. The presence of metabolic syndrome (MetS) was considered [18].

Laboratory investigations included complete blood picture, erythrocyte sedimentation rate, C-reactive protein, liver and kidney functions, thyroid stimulating hormone (TSH), parathormone (PTH), alkaline phosphatase (ALP), glycated hemoglobin (HbA1c), lipid profile, rheumatoid factor, anticitrullinated cyclic peptide, serum calcium, and 25-hydroxy vitamin D.

\section{Vitamin D receptor gene genotyping}

A total of $2 \mathrm{~mL}$ of fresh whole blood was collected in EDTA-containing tubes and stored in $-80^{\circ} \mathrm{C}$. The genomic DNA was isolated using the isolation kit (Qiagen, Germany). DNA samples were stored at $-20^{\circ} \mathrm{C}$; DNA concentration was determined using a NanoDrop lite Spectrophotometer (Thermo Scientific). Genotyping of Fok-I (rs2228570) and Taq-I (rs731236) was performed using TaqMan SNP Genotyping Assay. Real-time polymerase chain reaction (PCR) was performed using $5 \mu \mathrm{L}$ TaqMan Genotyping Master Mix $(2 \times), 0.5 \mu \mathrm{L}$ TaqMan SNP Genotyping Assay (TaqMan probes) $(20 \times), 3.5 \mu \mathrm{L}$ DNase Free Water, and $1 \mu \mathrm{L}$ DNA (50 ng), to bring the final reaction volume to $15 \mu \mathrm{L}$. PCR consisted of a hot starts at $95{ }^{\circ} \mathrm{C}$ for 10 min followed by 40 cycles of $94{ }^{\circ} \mathrm{C}$ for $15 \mathrm{~s}$ and $60{ }^{\circ} \mathrm{C}$ for $1 \mathrm{~min}$. All assays were performed using TaqMan Genotyping Master Mix on 96-well plates.

The BMD was assessed using the DXA scan (Lunar Prodigy, Madison, WI, USA) at the lumbar spine L1-L4, left femoral neck, and forearm. BMD measurement at or below - 2.5 SD from the optimal peak bone density of healthy young adult of the same sex was considered osteoporotic [10]. The patient with the most reduced BMD in the spine, femur, or forearm was categorized as having osteopenia or osteoporosis accordingly. TBS is a DXA-derived parameter based on the gray-level analysis that measures the microarchitecture or bone tissue distribution. TBS is good if the distribution of spaces is uniform. Lumbar spine (LS) TBS $T$-scores were calculated through the TBS iNsight software (Medimaps group, France) version 3.0 and were performed on the same vertebrae as those used for the BMD measurements.

The FRAX was computed using the algorithm available online at http://www.shef.ac.uk/FRAX (calculating the mean 
Jordanian and Turkish tools) with 9 clinical variables: age, BMI, previous fracture, hip fracture in a parent, alcohol use, smoking status, systemic glucocorticoids, RA, secondary osteoporosis, and femoral neck BMD.

\section{Statistical analysis}

Data was collected and analyzed using the Statistical Package for the Social Sciences (SPSS) software version 22. Data was presented as numbers and percentages or mean and standard deviation. Normality of distribution was considered using the one-sample Kolmogorov-Smirnov test. For comparisons, the independent samples $t$-test, chi-square test, and one-way ANOVA test were used. The Spearman correlation test was considered to test the association between quantitative variables. Regression analysis was conducted to determine the independent risk factors predicting osteoporosis. ROC curve was analyzed for VDR gene expression as a predictor for RA. The $p$-value $<0.05$ was considered significant.

\section{Results}

This study included 97 RA patients: 85 (87.6\%) females and $12(12.4 \%)$ males $(7.1: 1)$ with a mean age of $47.9 \pm 8.9$ years (35-70 years). The 45 controls were age ( $45.9 \pm 8.1$ years) and sex (39 females and 6 males; F:M 6.5:1) matched ( $p=0.18$ and $p=0.88$, respectively). Characteristics, osteoporotic risk factors, DEXA, TBS, and FRAX of patients and controls are presented in Table 1 and Fig. $1.86 .6 \%$ of patients vs $31.1 \%$ control were not working $(p<0.0001)$ while $76.3 \%$ were married vs $91.1 \%(p=0.01)$. Twentyeight patients had their faces only exposed to the sun while 7 patients and 3 controls had their faces, arms, and legs exposed. The mean tender joint count (TJC) in the patients was $7.6 \pm 6.9$ and swollen joint count (SJC) was $1.6 \pm 2.2$. According to the DAS28, 61 (62.9\%) had moderate, 27 (27.8\%) high, and $6(6.2 \%)$ low activity, while $3(3.1 \%)$ were in remission.

The laboratory investigations and mediations received by the patients are presented in Table 2 . The vitamin D level was comparable with the control $(9.3 \pm 6.5$ vs $10.4 \pm 7.5 \mathrm{ng} /$ $\mathrm{mL}, p=0.4)$. None of the patients was receiving anti-osteoporotic therapy or biologic therapy.

A comparison of the characteristics of the RA patients according to the BMD is presented in Table 3. On comparing the various parameters according to the VDR genotyping, the DEXA T-scores, TBS, and FRAX were similar. All the osteoporotic risk factors, DAS28, MHAQ, vitamin D level, RF, and anti-CCP were comparable. Only the ESR and CRP were significantly higher in those with rs 2228570 AA genotype $(73.4 \pm 17.4 \mathrm{~mm} / 1 \mathrm{~h}$ and $63.3 \pm 22.7 \mathrm{mg} / \mathrm{dL})$ compared to those with GG and AG $(39.5 \pm 16.7 \mathrm{~mm} / 1 \mathrm{~h}$, $25.5 \pm 9.6 \mathrm{mg} / \mathrm{dL}$ and $47.4 \pm 21.7 \mathrm{~mm} / 1 \mathrm{~h}, 33.9 \pm 16.9 \mathrm{mg} /$ $\mathrm{dL} ; p=0.002$ and $p<0.0001$ ).

The TBS was significantly lower and FRAX (major and hip) higher in patients with positive RF $(1.4 \pm 0.2$, $4.9 \pm 2.5$, and $0.8 \pm 0.8$ ) compared to those with negative $(1.5 \pm 0.1,3.9 \pm 1.9$, and $0.4 \pm 0.6 ; p=0.001, p=0.026$, and $p=0.008$ ). Those with positive anti-CCP had a significantly lower BMD (spine, femur, and forearm) and TBS and higher $\operatorname{FRAX}(-1.21 .3,-0.7 \pm 1.2,-2.5 \pm 1.2,1.4 \pm 0.2,4.9 \pm 2.5$, and $0.8 \pm 0.8)$ compared to those negative $(-0.2 \pm 1.7$, $0.3 \pm 0.8,-1.8 \pm 1.3,1.5 \pm 0.1,3.7 \pm 1.5$, and $0.4 \pm 0.5$; $p=0.02, p<0.0001, p=0.027, p=0.002, p=0.005$, and $p=0.001$ ). The FRAX for major OP \# was significantly higher in those receiving steroids $(5.6 \pm 2.2)$ compared to those not $(4.4 \pm 2.4 ; p=0.045)$; the femur $T$-score was significantly lower in those on LFN $(-0.5 \pm 1.2)$ compared to those not $(0.4 \pm 0.2 ; p=0.001)$ and the $T$-score spine was lower in those receiving HCQ $(-0.9 \pm 1.5)$ compared to those not $(-1.7 \pm 0.5 ; p=0.006)$.

Correlations of the patients' and disease characteristics with the TBS and FRAX in RA patients are shown in Table 4 . The TBS in patients significantly correlated with the FRAX $(r=-0.49, p<0.0001)$ (Fig. 2).

There was a significant association between considering a diet rich in calcium $(\beta 0.5,95 \%$ CI $0.01-0.99 ; p=0.046)$, the presence of metabolic syndrome $(\beta-1.45,95 \% \mathrm{CI}-2.58$ to $-0.31 ; p=0.015)$, and dyslipidemia $(\beta 1.18,95 \% \mathrm{CI}$ $0.26-2.1 ; p=0.014$ ) with the risk of osteoporosis in RA. The VDR rs2228570 genotyping (FokI) could not predict RA disease from control (AUC 0.43, 95\% CI 0.32-0.53; $p=0.15$ ) or patients with and without osteoporosis (AUC $0.48,95 \%$ CI $0.37-0.6 ; p=0.8$ ). Only the age at onset and receiving MTX would significantly predict the TBS in RA patients (AUC 0.91, 95\% CI 0.85-0.98; $p=0.04$ and AUC $0.95,95 \%$ CI $0.89-1 ; p=0.03)$.

\section{Discussion}

The coexistence of RA and osteoporosis is common and can lead to serious complications. The role of vitamin D and vitamin D receptor (VDR) gene polymorphisms in RA pathogenesis and clinical course of the disease has been investigated, with controversial data according to many factors including genetic, ethnicity, and environmental factors [19].

The current study showed that there was a significant difference between patients and controls as regards DXA, TBS, and FRAX. A lower BMD in RA patients compared to controls has been shown with an increased prevalence of osteoporosis [20]. The effectiveness of TBS for assessing the fracture risk in RA has been evaluated [21]. This was 
Table 1 Characteristics, osteoporotic risk factors, dualenergy X-ray absorptiometry (DEXA), trabecular bone score (TBS), fracture risk assessment (FRAX) in 10 years, and vitamin D receptor (VDR) genotype in rheumatoid arthritis patients and controls

\begin{tabular}{|c|c|c|c|c|c|}
\hline Variables, mean $\pm \mathrm{SD}$ or $n(\%)$ & RA cases $(n=97)$ & & Control $(n=45)$ & & $p$ \\
\hline Age (years) & 47.9 & \pm 8.9 & 45.9 & \pm 8.1 & 0.18 \\
\hline \multicolumn{6}{|l|}{ Sex } \\
\hline Female:male & $88: 12$ & & $39: 6$ & & 0.88 \\
\hline Disease duration (years) & $9.4 \pm 6.2(1-25)$ & & - & & - \\
\hline Age at onset (years) & $38.4 \pm 9(20-62)$ & & - & & - \\
\hline Smoking & 5 & $(5.2)$ & 3 & $(6.7)$ & 0.73 \\
\hline BMI & 26.4 & \pm 3.5 & 27.1 & \pm 3.5 & 0.24 \\
\hline Menopausal & 34 & $(35.1)$ & 9 & $(20)$ & 0.049 \\
\hline Menopause age (years) & 46.3 & \pm 3.6 & 47.4 & \pm 1.7 & 0.17 \\
\hline Diet rich in calcium & 21 & $(21.6)$ & 6 & $(13.3)$ & 0.21 \\
\hline Sun exposure & 35 & $(36.1)$ & 3 & $(6.7)$ & $<0.0001$ \\
\hline Prior fracture & 10 & & $0(0)$ & & - \\
\hline Co-morbidities & $17(17.5)$ & & $0(0)$ & & - \\
\hline Metabolic syndrome & $6(6.2)$ & & $0(0)$ & & - \\
\hline MHAQ & $0.6 \pm 0.4(0.1-1.8)$ & & - & & - \\
\hline DAS28 & $4.52 \pm 1.04$ & & - & & - \\
\hline \multicolumn{6}{|l|}{ DEXA } \\
\hline \multicolumn{6}{|l|}{ Spine } \\
\hline T-score & $-0.99 \pm 1.46$ & & $1.8 \pm 0.27$ & & $<0.0001$ \\
\hline Osteopenia & $38(39.2)$ & & $4(8.9)$ & & 0.008 \\
\hline Osteoporosis & $9(9.3)$ & & $4(8.9)$ & & \\
\hline \multicolumn{6}{|l|}{ Femur } \\
\hline T-score & $-0.46 \pm 1.18$ & & $1.06 \pm 1.44$ & & $<0.0001$ \\
\hline Osteopenia & $24(24.7)$ & & $6(13.3)$ & & 0.051 \\
\hline Osteoporosis & $1(1)$ & & $0(0)$ & & \\
\hline \multicolumn{6}{|l|}{ Forearm } \\
\hline$T$-score & $-2.36 \pm 1.22$ & & $-0.61 \pm 1.28$ & & $<0.0001$ \\
\hline Osteopenia & $47(48.5)$ & & $12(26.7)$ & & $<0.0001$ \\
\hline Osteoporosis & $43(44.3)$ & & $1(2.2)$ & & \\
\hline TBS & $1.49 \pm 0.16$ & & $1.46 \pm 0.15$ & & 0.29 \\
\hline \multicolumn{6}{|l|}{ Degradation } \\
\hline Partial & $15(15.5)$ & & $9(20)$ & & 0.57 \\
\hline Severe & $2(2.1)$ & & $1(2.2)$ & & \\
\hline \multicolumn{6}{|l|}{ FRAX } \\
\hline Major OP \# & $4.65 \pm 2.36$ & & $2.42 \pm 0.95$ & & $<0.0001$ \\
\hline Hip \# & $0.73 \pm 0.75$ & & $0.17 \pm 0.33$ & & $<0.0001$ \\
\hline \multicolumn{6}{|l|}{ VDR genotype } \\
\hline \multicolumn{6}{|l|}{ rs2228570 (FokI) } \\
\hline GG & $59(60.8)$ & & $21(46.7)$ & & 0.12 \\
\hline $\mathrm{AG}$ & $33(34)$ & & $20(44.4)$ & & \\
\hline AA & $5(5.2)$ & & $4(8.9)$ & & \\
\hline \multicolumn{6}{|l|}{ rs731236 (TaqI) } \\
\hline $\mathrm{AG}$ & $97(100)$ & & $45(100)$ & & - \\
\hline
\end{tabular}

Bold values are significant at $p<0.05$

$R A$, rheumatoid arthritis; $B M I$, body mass index; TJC, tender joint count; SJC, swollen joint count; DAS28, disease activity score; $M H A Q$, modified health assessment questionnaire; $D E X A$, dual energy x-ray absorptiometry; TBS, trabecular bone score; FRAX, fracture risk assessment in 10 years; OP, osteoporosis; \#, fracture; $V D R$, vitamin D receptor 

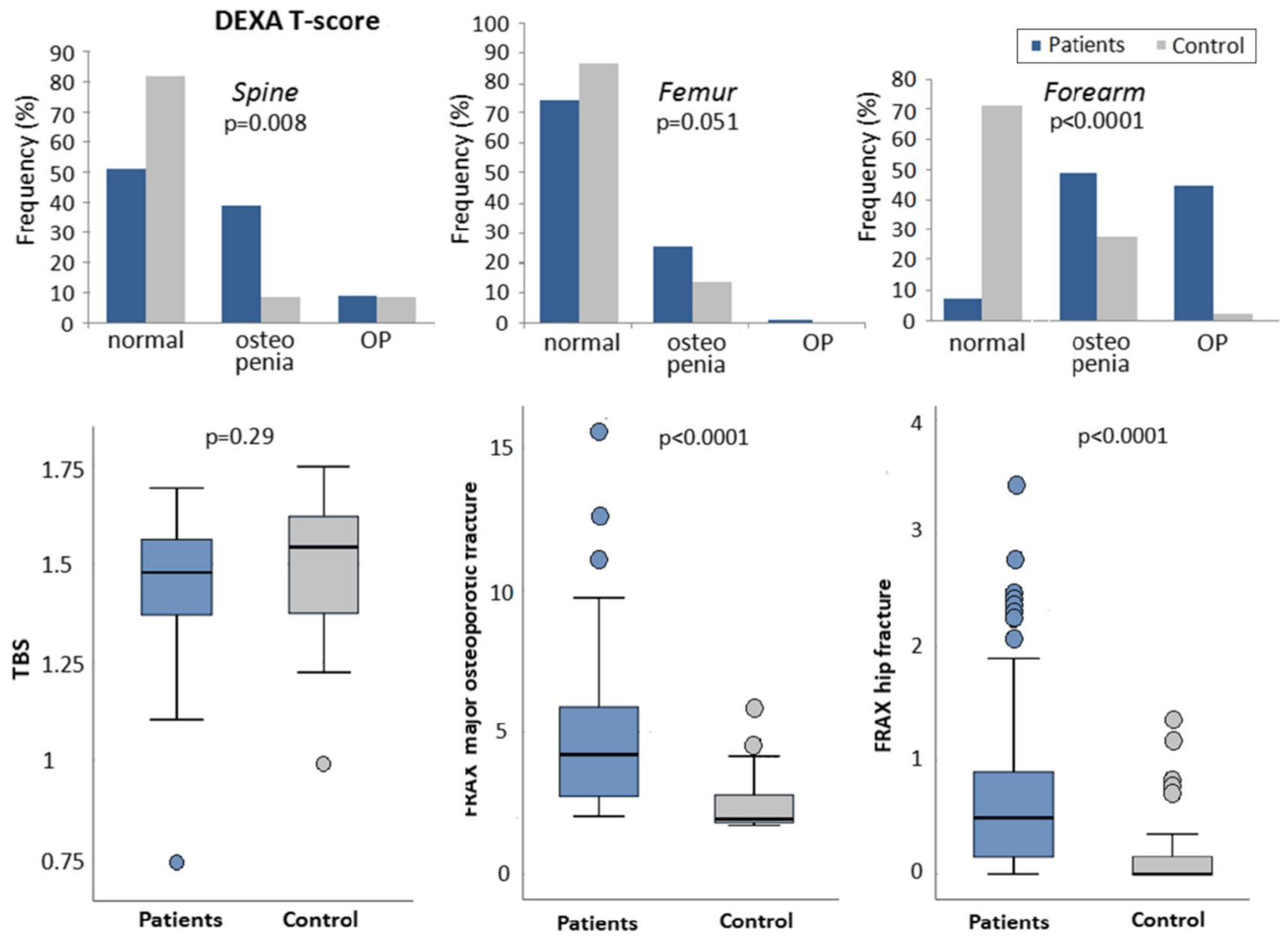

Fig. 1 Dual-energy X-ray absorptiometry (DEXA), trabecular bone score (TBS), and fracture risk assessment (FRAX) in 10 years in rheumatoid arthritis patients and controls

confirmed by Choi et al. [22] who revealed that vertebral fractures can be observed in the first year of the disease and one-third report a fracture within 5 years of follow-up. Syngle and colleagues showed that active RA patients have increased FRAX score, even in the absence of BMD findings indicating increased 10-years probability of major osteoporotic fracture and hip fracture [23]. A meta-analysis of 13 studies showed a significant higher risk of bone fracture in patients with RA with a higher frequency of vertebral and hip fracture [24]. However, in another study, the FRAX estimated with and without BMD may vary substantially in RA patients [25]. It should be considered that FRAX has some limitations. It does not consider, for example, the number of previous fractures, doses of glucocorticoids, and smoking or alcohol and does not include lumbar spine BMD or the number of falls [26].

There was no significant difference between cases and controls as regards vitamin D level as most of them had deficiency. Similarly, other studies demonstrated that there was no significant difference in serum vitamin D level in RA and controls [27, 28]. Vitamin D deficiency was present in almost all Egyptian healthy adolescents [29] and prevalent among Egyptian women of childbearing age [30]. There was a significant association between lack of physical activity, sun exposure, and vitamin D deficiency. Although Egypt is a sunny country, such vitamin D deficiency could be attributed to the special pattern of conservative clothing and the lack of outdoor physical activity in females. Vitamin D supplementation seems to be mandatory to halt the problem [29]. In contrast, others showed significant inverse correlation between vitamin D and disease onset in RA [31, 32]. Elbassiony et al. [33] have detected that the serum vitamin D in RA patients was significantly lower than that of controls.

A series of polymorphisms in VDR gene have been reported. They include BsmI, ApaI, TaqI restriction sites, variable PolyA length, and FokI restriction site. Of these polymorphic sites, BsmI are substitutions on intron 8 whereas ForkI restriction enzyme identifies a polymorphic site in exon 2 at the 50 ends of the VDR gene. They have an effective role, a functional significance of these polymorphisms, 
Table 2 Laboratory investigations among rheumatoid arthritis cases

\begin{tabular}{|c|c|c|c|}
\hline Mean \pm SD (range) or $n(\%)$ & \multicolumn{2}{|l|}{ RA patients $(n=97)$} & \\
\hline \multicolumn{4}{|l|}{ Laboratory investigations } \\
\hline Hemoglobin (g/dL) & $11.6 \pm 1.2$ & & Anemia: 48 (49.5) \\
\hline $\operatorname{TLC}\left(\times 10^{3} / \mathrm{mm}^{3}\right)$ & $6.5 \pm 1.8$ & & Leukopenia: 4 (4.1) \\
\hline Platelets $\left(\times 10^{3} / \mathrm{mm}^{3}\right)$ & $288.1 \pm 64.7$ & & Thrombocytopenia: 6 (6.2) \\
\hline $\mathrm{ESR}(\mathrm{mm} / \mathrm{h})$ & $46.1 \pm 21.1$ & & 个ESR: 76 (78.4) \\
\hline $\mathrm{CRP}(\mathrm{mg} / \mathrm{L})$ & $33.1 \pm 17.7$ & & Positive CRP: 51 (52.6) \\
\hline ALT (IU/L) & $22.1 \pm 10.9$ & & $\uparrow$ LFT: 12 (12.4) \\
\hline AST (IU/L) & $24.8 \pm 11.4$ & & \\
\hline Creatinine (mg/dL) & $0.81 \pm 0.56$ & & Normal in all \\
\hline Serum uric acid (mg/dL) & $3.8 \pm 0.95$ & & Normal in all \\
\hline Cholesterol (mg/dL) & $145.9 \pm 33.4$ & & Dyslipidemia: 10 (10.3) \\
\hline Triglycerides (mg/dL) & $90.6 \pm 38.7$ & & \\
\hline LDL (mg/dL) & $79.3 \pm 14.2$ & & \\
\hline HDL (mg/dL) & $66.3 \pm 13.6$ & & \\
\hline TSH (mIU/L) & $1.42 \pm 1.4$ & & $\uparrow: 2(2.1) / \downarrow: 14(14.3)$ \\
\hline PTH (pg/mL) & $41.3 \pm 31.6$ & & $\uparrow: 5(5.2) / \downarrow: 2(2.1)$ \\
\hline Rheumatoid factor (IU/mL) & $37.1 \pm 18.5$ & & Positive: 71 (73.2) \\
\hline Anti CCP (AU/mL) & $132.9 \pm 118.9$ & & Positive: 75 (77.3) \\
\hline \multicolumn{4}{|l|}{ Calcium } \\
\hline Total (mg/dL) & $9.3 \pm 0.62$ & & $\downarrow: 18$ (18.6) \\
\hline Ionized (mg/dL) & $4.6 \pm 0.62$ & & $\downarrow: 16(16.5)$ \\
\hline ALP (U/L) & $75.9 \pm 40.3$ & & $\uparrow A L P: ~ 8$ (8.2) \\
\hline Vitamin D (ng/mL) & $9.3 \pm 6.5(2.2-33)$ & & Def. 69 (71.1)/insuff:: 27 (27.8) \\
\hline \multicolumn{4}{|l|}{ Medications/Supplements } \\
\hline Methotrexate & 11 & $(11.3)$ & \\
\hline Leflunomide & 94 & $(97)$ & \\
\hline Hydroxychloroquine & 90 & $(92.8)$ & \\
\hline Steroids & 20 & $(20.6)$ & Cumm. dose $(\mathrm{mg}): 72.7 \pm 64.1$ \\
\hline Calcium & 46 & $(47.4)$ & \\
\hline Vitamin D & 6 & $(6.2)$ & \\
\hline
\end{tabular}

$R A$, rheumatoid arthritis; $T L C$, total leukocytic count; $E S R$, erythrocyte sedimentation rate; $C R P$, C-reactive protein; $A L T$, alanine transferase; $A S T$, aspartate transaminase; $T S H$, thyroid stimulating hormone; $P T H$, parathyroid stimulating hormone; Anti-CCP, anti-cyclic citrullinated peptide; $A L P$, alkaline phosphatase

wwwand their potential effects on RA susceptibility [34]. The current study showed that VDR genotyping rs 2,228,570 (Fok-I) was similar between patients and control with a tendency to a higher frequency of GG genotype. There was no significant difference as regards rs731236 (Taq-I) genotyping between patients and controls. In harmony, genetic analysis of four VDR polymorphisms, BsmI, FokI, ApaI, and TaqI did not confer the susceptibility to RA in Lithuanian population [19]. However, it has been reported that there was a significant higher percentage of (Fok-I) genotyping among RA cases versus controls but not BsmI [35]. The frequencies CGAT, CGGA, CGGT, CTAA, CTAT, TGAA, TGAT, TGGA, and TTGA haplotypes were higher in patients and act as risk factors of RA onset [28]. A recent study revealed that VDR Fok1 (rs10735810) polymorphism had an association with RA, while VDR Bsm1 (rs1544410) polymorphism has not [36].

It was detected in the current study that there was a significant difference relation of VDR genotype (Fok-I) and CRP levels among cases but not with other parameters. Virtually, all immune cells express VDR, making them susceptible to vitamin D-mediated modulation, so after binding to VDR, active vitamin $\mathrm{D}$ has a direct immunosuppressive effect on dendritic cells, reduces CD4 + cells proliferation, and differentiation into Th1 and Th17. VDR agonists were proposed to be selective inhibitors of Th1 cell development and found to inhibit Th1-type cytokines such as IL- 2 and TNF- $\alpha$ directly [37]. Furthermore, a study found that variants of FokI Ff genotype were associated with a higher CRP concentration in RA subjects [19]. 
Table 3 Characteristics of the rheumatoid arthritis patients according to the bone mineral density

\begin{tabular}{|c|c|c|c|c|}
\hline \multirow[t]{2}{*}{ Variables, mean \pm SD or $n(\%)$} & \multicolumn{3}{|c|}{ BMD in RA patients $(n=97)$} & \multirow[t]{2}{*}{$p$} \\
\hline & Normal $(n=6)$ & Osteopenia $(n=48)$ & OP $(n=43)$ & \\
\hline Age (years) & $38.2 \pm 2.4$ & $45.8 \pm 6.6$ & $51.7 \pm 10$ & $<0.0001$ \\
\hline Disease duration (years) & $4.2 \pm 2.8$ & $7.5 \pm 5.4$ & $12.3 \pm 6.3$ & $<0.0001$ \\
\hline BMI & $26.7 \pm 1.5$ & $26.6 \pm 3.8$ & $26.1 \pm 3.3$ & 0.76 \\
\hline Smoking & $0(0)$ & $4(8.3)$ & $1(2.3)$ & 0.37 \\
\hline Passive smoking & $2(33.3)$ & $14(29.2)$ & $16(37.2)$ & 0.72 \\
\hline Menopausal & $0(0)$ & $13(27.1)$ & $21(48.8)$ & 0.005 \\
\hline Diet rich in calcium & $3(50)$ & $8(16.7)$ & $10(23.3)$ & 0.17 \\
\hline Sun exposure & $2(33.3)$ & $12(25)$ & $21(48.8)$ & 0.06 \\
\hline $\mathrm{ESR}(\mathrm{mm} / \mathrm{L} \mathrm{h})$ & $39.2 \pm 15.3$ & $46.8 \pm 21.5$ & $46.2 \pm 21.6$ & 0.71 \\
\hline $\mathrm{CRP}(\mathrm{mg} / \mathrm{dL})$ & $3(50)$ & $25(52.1)$ & $23(53.5)$ & 0.98 \\
\hline RF positive & $1(16.7)$ & $36(75)$ & $34(79.1)$ & 0.004 \\
\hline Anti-CCP positive & $3(50)$ & $35(72.9)$ & $37(86)$ & 0.09 \\
\hline TSH (mIU/L) & $0.98 \pm 0.8$ & $1.4 \pm 1.5$ & $1.5 \pm 1.4$ & 0.72 \\
\hline PTH (pg/mL) & $38.3 \pm 9.6$ & $40.1 \pm 20.6$ & $43.1 \pm 42.3$ & 0.88 \\
\hline Vitamin D (ng/mL) & $13.5 \pm 9.2$ & $8.9 \pm 6$ & $9.3 \pm 6.5$ & 0.26 \\
\hline DAS-28 & $4.6 \pm 0.59$ & $4.6 \pm 0.88$ & $4.4 \pm 1.3$ & 0.79 \\
\hline MHAQ & $0.25 \pm 0.19$ & $0.58 \pm 0.4$ & $0.62 \pm 0.4$ & 0.11 \\
\hline Steroids & $0(0)$ & $11(22.9)$ & $9(20.9)$ & 0.43 \\
\hline Methotrexate & $0(0)$ & $5(10.4)$ & $6(14)$ & 0.59 \\
\hline Leflunomide & $6(0)$ & 47 (97.9) & $41(95.3)$ & 0.71 \\
\hline Hydroxychloroquine & $6(100)$ & $45(83.8)$ & $39(90.7)$ & 0.8 \\
\hline
\end{tabular}

Bold values are significant at $p<0.05$

$B M D$, bone mineral density; $R A$, rheumatoid arthritis; $B M I$, body mass index; $E S R$, erythrocyte sedimentation rate; $C R P$, C-reactive protein; $R F$, rheumatoid factor; Anti-CCP, anti-cyclic citrullinated peptide; $T S H$, thyroid stimulating hormone; $P T H$, parathyroid stimulating hormone; $D A S 28$, disease activity score; $M H A Q$, modified health assessment questionnaire
There was a significant association between the presence of osteoporosis and age, disease duration, presence of menopause, and RF positivity. The TBS was significantly lower and FRAX higher in patients with positive RF. Those with positive anti-CCP had a significantly lower BMD and TBS as well as a higher FRAX. The FRAX for major OP \# was significantly higher in those receiving steroids; the femur $T$-score was significantly lower in those on LFN and the $T$-score spine was lower in those receiving HCQ. The FRAX was significantly related and the TBS inversely with the age, disease duration, SUA, ALP, and MHAQ. The FRAX was further significantly related to the LDL level and the TBS negatively with the anti-CCP titre. In concordance, Haugeberg et al. showed that reduced BMD was associated with age, current use of corticosteroids, physical disability, and RF positivity in RA [20]. Lee and colleagues reported that postmenopausal patients with RA $46.8 \%$ were osteoporotic with a higher frequency of previous fractures, especially of the femur and wrist. They further added that advanced age, longer disease duration, higher cumulative dose of steroids, and higher HAQ score were significant key players associated with osteoporosis [38]. Choi et al. [39] revealed that osteoporotic fractures were detected in $16.9 \%$ of postmenopausal patients; female gender, age, disease duration, and steroids dose were independent risk factors for fracture. In Tunisian RA patients, bone loss was significantly associated with age, longer disease duration, RF, atlantoaxial subluxation, and corticosteroids use. The risk of multiple osteoporotic and hip fracture was associated with age, menopause, calcium intake, disease duration, HAQ, cumulative dose, and duration of corticosteroids [40].

Kwok and others concluded that all men (aged $\geq 70$ years) and women (aged $\geq 65$ years) should receive universal DEXA assessment for osteoporosis and those with an increased FRAX should receive anti-osteoporotic treatment to prevent hip fractures [41].

Among the study limitations is the relatively small sample size and assessing only two VDR genes for their association with the risk of bone loss. So, further multi-center research is necessary among larger cohorts, involving different geographical distribution.

In conclusion, the reduced BMD and increased tendency to fractures are remarkable in RA patients. Vitamin D level was decreased in patients and control, and the 
Table 4 Correlations of the patients' and disease characteristics with the trabecular bone score (TBS) and fracture risk assessment (FRAX) in 10 years in rheumatoid arthritis patients

\begin{tabular}{|c|c|c|c|}
\hline \multirow[t]{3}{*}{ Variable, $r(p)$} & \multicolumn{3}{|c|}{ RA patients $(n=97)$} \\
\hline & \multirow[t]{2}{*}{ TBS } & \multicolumn{2}{|l|}{ FRAX } \\
\hline & & Major OP \# & Hip \# \\
\hline Age (years) & $\begin{array}{l}-0.55 \\
(<\mathbf{0 . 0 0 0 1 )}\end{array}$ & $0.69(<\mathbf{0 . 0 0 0 1})$ & $0.74(<\mathbf{0 . 0 0 0 1})$ \\
\hline $\begin{array}{l}\text { Disease } \\
\text { duration }\end{array}$ & $-0.27(\mathbf{0 . 0 0 7})$ & $0.3(\mathbf{0 . 0 0 3})$ & $0.31(\mathbf{0 . 0 0 2})$ \\
\hline BMI & $0.04(0.73)$ & $-0.15(0.15)$ & $-0.29(\mathbf{0 . 0 0 4 )}$ \\
\hline $\operatorname{ESR}(\mathrm{mm} / 1 \mathrm{~h})$ & $-0.16(0.13)$ & $0.13(0.22)$ & $0.13(0.22)$ \\
\hline CRP (mg/dL) & $-0.12(0.39)$ & $-0.01(0.96)$ & $0.06(0.7)$ \\
\hline $\begin{array}{l}\text { Hemoglobin }(\mathrm{g} / \\
\mathrm{dL})\end{array}$ & $0.13(0.22)$ & $-0.15(0.15)$ & $-0.16(0.13)$ \\
\hline $\begin{array}{l}\operatorname{TLC}\left(\times 10^{3} /\right. \\
\left.\mathrm{mm}^{3}\right)\end{array}$ & $0.09(0.4)$ & $0.04(0.67)$ & $-0.1(0.35)$ \\
\hline $\begin{array}{l}\text { Platelet }\left(\times 10^{3} /\right. \\
\left.\mathrm{mm}^{3}\right)\end{array}$ & $-0.11(0.27)$ & $0.1(0.32)$ & $-0.01(0.91)$ \\
\hline $\begin{array}{l}\text { Creatinine (mg/ } \\
\text { dL) }\end{array}$ & $-0.05(0.65)$ & $0.09(0.41)$ & $0.15(0.15)$ \\
\hline SUA (mg/dL) & $-0.32(\mathbf{0 . 0 0 1})$ & $0.23(\mathbf{0 . 0 3})$ & $0.21(\mathbf{0 . 0 4})$ \\
\hline LDL (mg/dL) & $-0.1(0.31)$ & $0.22(\mathbf{0 . 0 3})$ & $0.21(\mathbf{0 . 0 3 6 )}$ \\
\hline \multicolumn{4}{|l|}{ Calcium } \\
\hline Total & $0.04(0.67)$ & $0.02(0.83)$ & $-0.03(0.75)$ \\
\hline Ionized & $0.05(0.64)$ & $-0.12(0.24)$ & $-0.14(0.18)$ \\
\hline ALP (U/L) & $-0.27(\mathbf{0 . 0 0 8})$ & $0.23(\mathbf{0 . 0 2})$ & $0.32(\mathbf{0 . 0 0 2})$ \\
\hline RF (IU/mL) & $0.05(0.68)$ & $-0.05(0.7)$ & $-0.12(0.3)$ \\
\hline $\begin{array}{l}\text { Anti-CCP (AU/ } \\
\text { mL) }\end{array}$ & $-0.3(\mathbf{0 . 0 0 8})$ & $0.15(0.2)$ & $0.13(0.26)$ \\
\hline TSH (mIU/L) & $0.11(0.29)$ & $0.12(0.25)$ & $0.14(0.18)$ \\
\hline PTH (pg/mL) & $-0.2(0.055)$ & $-0.02(0.88)$ & $-0.08(0.47)$ \\
\hline $\begin{array}{l}\text { Vitamin D (ng/ } \\
\text { mL) }\end{array}$ & $0.06(0.53)$ & $-0.08(0.42)$ & $0.07(0.47)$ \\
\hline DAS-28 & $-0.16(0.12)$ & $0.06(0.55)$ & $0.09(0.4)$ \\
\hline MHAQ & $\begin{array}{l}-0.49 \\
(<\mathbf{0 . 0 0 0 1})\end{array}$ & $0.36(<\mathbf{0 . 0 0 0 1})$ & $0.32(<\mathbf{0 . 0 0 0 1})$ \\
\hline
\end{tabular}

Bold values are significant at $p<0.05$

$R A$, rheumatoid arthritis; TBS, trabecular bone score; FRAX, fracture risk assessment in 10 years; $O P$, osteoporosis; \#, fracture; $E S R$, erythrocyte sedimentation rate; $C R P, \mathrm{C}$-reactive protein; $T L C$, total leukocytic count; $S U A$, serum uric acid; $L D L$, low density lipoprotein; $A L P$, alkaline phosphatase; $R F$, rheumatoid factor; Anti-CCP, anticitrullinated cyclic peptide; TSH, thyroid stimulating hormone; $P T H$, parathyroid stimulating hormone; DAS28, disease activity score; $M H A Q$, modified health assessment questionnaire

VDR gene polymorphism Fok-I and Taq-1 were not linked to RA. TBS and FRAX are effective tools to assess osteoporotic fractures in RA. Bone loss and fragility fracture are

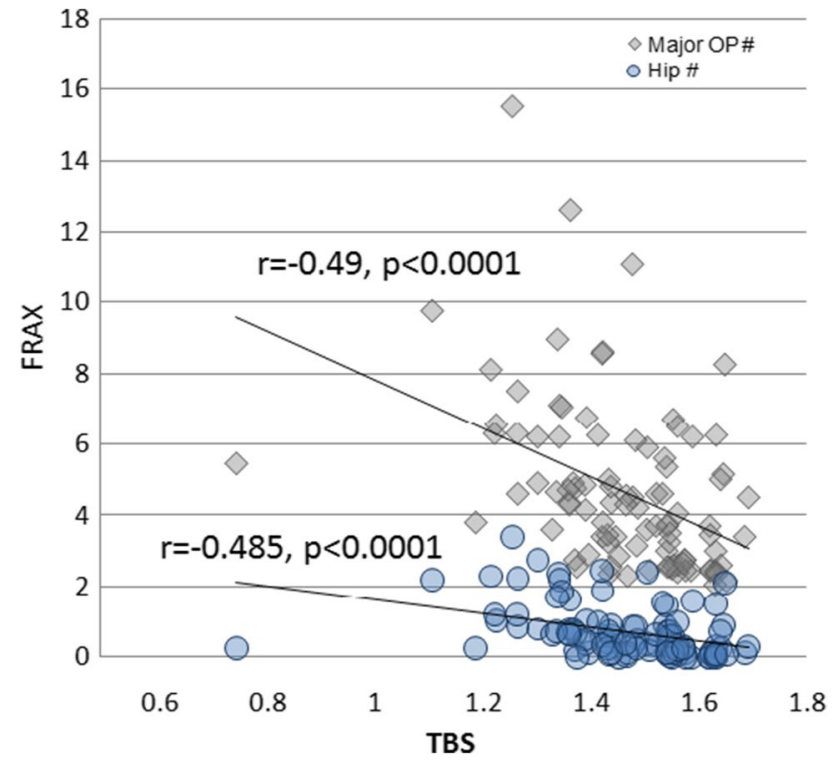

Fig. 2 Correlation of the trabecular bone score (TBS) with the FRAX (major osteoporotic fracture and hip fracture) in rheumatoid arthritis patients

related to age, disease duration, menopause, SUA, RF and anti-CCP positivity, function impairment, and steroids.

Funding Open access funding provided by The Science, Technology \& Innovation Funding Authority (STDF) in cooperation with The Egyptian Knowledge Bank (EKB).

\section{Declarations}

Disclosures None.

Open Access This article is licensed under a Creative Commons Attribution 4.0 International License, which permits use, sharing, adaptation, distribution and reproduction in any medium or format, as long as you give appropriate credit to the original author(s) and the source, provide a link to the Creative Commons licence, and indicate if changes were made. The images or other third party material in this article are included in the article's Creative Commons licence, unless indicated otherwise in a credit line to the material. If material is not included in the article's Creative Commons licence and your intended use is not permitted by statutory regulation or exceeds the permitted use, you will need to obtain permission directly from the copyright holder. To view a copy of this licence, visit http://creativecommons.org/licenses/by/4.0/. 


\section{References}

1. Guo Q, Wang Y, Xu D, Nossent J, Pavlos NJ, Xu J et al (2018) Rheumatoid arthritis: pathological mechanisms and modern pharmacologic therapies. Bone Res 6:15

2. Eriksen EF (2010) Cellular mechanisms of bone remodeling. Rev Endocr Metab Disord 11(4):219-227

3. Sims NA, Martin TJ (2014) Coupling the activities of bone formation and resorption: a multitude of signals within the basic multicellular unit. Bone Key Rep 3:481

4. Hamilton CJ, Reid LS, Jamal SA (2013) Organic nitrates for osteoporosis: an update. Bone Key Rep 2:259

5. Gheita TA, Fathi HM (2018) Biologics for osteoporosis: where do we stand? J Musculoskelet Disord Treat 4:059

6. Ranganathan P (2009) Genetics of bone loss in rheumatoid arthritis: role of vitamin D receptor polymorphisms. Rheumatology (Oxford) 48:342-346

7. DI Spigna G, Del Puente A, Covelli B, Abete E, Varriale E, Salzano $S$ et al (2016) Vitamin D receptor polymorphisms as tool for early screening of severe bone loss in women patients with rheumatoid arthritis. Eur Rev Med Pharmacol Sci 20:4664-4669

8. Rai V, Dietz NE, Dilisio MF, Radwan MM, Agrawal DK et al (2016) Vitamin D attenuates inflammation, fatty infiltration, and cartilage loss in the knee of hyperlipidemic microswine. Arthritis Res Ther 18:203

9. Chapurlat R (2013) Contributions and limitations of the FRAX tool. Joint Bone Spine 80:355-357

10. World Health Organization (1994) Assessment of fracture risk and its application to screening for postmenopausal osteoporosis: report of a WHO study group. [meeting held in Rome; 22-5 June 1992]. Geneva: World Health Organization. https://apps.who.int/ iris/handle/10665/39142

11. Seeman E, Delmas PD (2006) Bone quality: the material and structural basis of bone strength and fragility. N Engl J Med $354: 225 \mathrm{e} 061$

12. Compston J (2009) Monitoring osteoporosis treatment. Best Pract Res Clin Rheumatol 23:781e8

13. Hans D, Barthe N, Boutroy S, Pothuaud L, Winzenrieth R, Krieg MA et al (2011) Correlations between trabecular bone score, measured using anteroposterior dual energy X-ray absorptiometry acquisition, and 3-dimensional parameters of bone microarchitecture: an experimental study on human cadaver vertebrae. J Clin Densitom 14:302e12

14. Aletaha D, Neogi T, Silman AJ, Funovits J, Felson DT, Bingham CO 3rd et al (2010) 2010 Rheumatoid arthritis classification criteria: an American College of Rheumatology/European League Against Rheumatism collaborative initiative. Arthritis Rheum 62(9):2569-2581

15. Hawker GA, Main S, Kendzerska T, French M (2011) Measure of adult pain: visual analog scale for pain (VAS), numeric rating scale for pain (NRS pain), McGill pain questionnaire (MPQ), short -form McGill pain questionnaire (SF-MPQ), chronic pain grade scale (CPGS), short form-36 bodily pain scale (SF-36 BPS), and measure of intermittent and constant osteoarthritis pain (ICOAP). Arthritis Care Res (Hoboken) 63(Suppl):S240-S252

16. Pincus T, Sokka T, Kautiainen H (2005) Further development of a physical function scale on a MDHAQ [corrected] for standard care of patients with rheumatic diseases. J Rheumatol 32(8):1432-1439

17. Aletaha D, Ward MM, Machold KP, Nell VP, Stamm T, Smolen JS (2005) Remission and active disease in rheumatoid arthritis: defining criteria for disease activity states. Arthritis Rheum 52(9):2625-2636

18. Hallajzade J, Safiri S, Mansourni MA, Khoramdad M, Izadi N, Almasi-Hashiani A et al (2017) Metabolic syndrome and its components among rheumatoid arthritis patients: a comprehensive updated systematic review and meta-analysis. PLoS One 1-21

19. Punceviciene E, Gaizevska J, Sabaliauskaite R, Venceviciene L, Puriene A, Vitkus D et al (2021) Vitamin D and VDR gene polymorphisms' association with rheumatoid arthritis in Lithuanian Population. Medicina 57:346

20. Haugeberg G, Uhlig T, Falch JA, Halse JI, Kvien TK (2000) Bone mineral density and frequency of osteoporosis in female patients with rheumatoid arthritis. Arthritis Rheum 43:522-530

21. Breban S, Briot K, Kolta S, Paternotte S, Ghazi M, Fechtenbaum $\mathbf{J}$ et al (2012) Identification of rheumatoid arthritis patients with vertebral fractures using bone mineral density and trabecular bone score. J Clin Densitom 15:260-266

22. Choi YJ, Chung YS, Suh CH, Jung JY, Kim HA (2017) Trabecular bone score as a supplementary tool for the discrimination of osteoporotic fractures in post menopausal women with rheumatoid arthritis. Medicine 96:45

23. Syngle T, Kaur S, Garg N (2018) Osteoporotic fracture risk in rheumatoid arthritis. Int J Pharm Pharm Sci 10(3):106-109

24. Xue AL, Wu SY, Jiang L, Feng AM, Guo HF, Zhao P (2017) Bone fracture risk in patients with rheumatoid arthritis: a meta-analysis. Medicine 96:e6983

25. Elde KD, Madsen OR (2019) FRAX 10-yr fracture risk in rheumatoid arthritis-assessments with and without bone mineral density may lead to very different results in the individual patient. J Clin Densitom 22(1):31-38

26 Gómez-Vaquero C, Fábregas-Canales D, Seoane-Mato D, Sánchez-Piedra C, Díaz-González F, Bustabad-Reyes S (2020) Fracture risk assessment in the general population in Spain by FRAX® algorithm. EPISER2016 study. Medicina Clínica 154(5):163-70

27. Hanvivadhanakul P, Singhea J (2017) The relationship of serum vitamin D level and disease activity in rheumatoid arthritis patients. J Med Assoc Thai 100(6):107

28 Mukhtar M, Sheikh N, Suqaina SK, Batool A, Fatima N, Mehmood R et al (2019) Vitamin D receptor gene polymorphism: an important predictor of arthritis development. BioMed Res Int 8326246:8

29. Sherief LM, Ali A, Gaballa A, Abdellatif GM, Kamal NM, Afify MR, Abdelmalek DH, El-Emari SA, Soliman ASA, Mokhtar WA (2021) Vitamin D status and healthy Egyptian adolescents: where do we stand? Medicine (Baltimore). 100(29):e26661

30. Gerges MES, Amin GEA, Andraous F, Abdel Hamid DM, Allam MF (2021) Vitamin D level in a sample of Egyptian females of childbearing age attending a family medicine center. Int J Clin Pract. 75(4):e13738

31 Lin J, Liu J, Davies ML, Chen W (2016) Serum vitamin D level and rheumatoid arthritis disease activity: review and meta-analysis. PLoS One 11:e0146351

32. Vojinovic J, Tincani A, Sullietal A (2017) European multicentre pilot survey to assess vitamin D status in rheumatoid arthritis patients and early development of a new Patient Reported Outcome questionnaire (D-PRO). Autoimmun Rev 16(5):548-554

33. Elbassiony SR, Tawhid Z, Ahmad HS, Sabry A (2016) Serum 25-hydroxy vitamin D levels in Egyptian patients with rheumatoid arthritis: association with disease activity, functional disability and radiological damage. Egyptian Rheumatologist 38:133-139 
34. Despotović M, Stoimenov TJ, Stojanović S, Bašić J, Kundalić J, Đorđević B et al (2021) Association of vitamin D receptor genetic variants with bone mineral density and inflammatory markers in rheumatoid arthritis. Clin Biochem 87:26-31

35. Karray EF, Dhifallah IB, Ben Abdelghani KB, Ghorbel IB, Khanfir M, Houman $\mathrm{H}$ et al (2012) Associations of vitamin D receptor gene polymorphisms FokI and BsmI with susceptibility to rheumatoid arthritis and Behçet's disease in Tunisians. J Bone Spine 79(2):144-148

36. Bharathi HU, Kalpana VL, Naidu AR, Kusuma BP, Anuradha A (2021) Association of vitamin D receptor gene polymorphisms in rheumatoid arthritis patients from north coastal Andhra Pradesh. Saudi J Biomed Res 6(7):199-206

37. Çomak E, Doğan CS, Uslu-Gökçeoğlul A, Akbaş H, Özdem S, Koyun M et al (2014) Association between vitamin D deficiency and disease activity in juvenile idiopathic arthritis. Turk J Pediatr $56: 626-31$

38. Lee JH, Sung YK, Choi CB, Cho SK, Bang SY, Choe JY et al (2016) The frequency and risk factors for osteoporosis in Korean patients with rheumatoid arthritis. BMC Musculoskelet Disord 17(98)

39. Choi ST, Kwon SR, Jung JY, Kim HA, Kimm SS, Kim SH et al (2018) Prevalence and fracture risk of osteoporosis in patients with rheumatoid arthritis: a multicenter comparative study of the FRAX and the WHO criteria. J Clin Med 7(12):507

40. Wafa H, Raja A, Dhia K, Nada B, Imene Z, Montacer KM (2019) Risk factors associated with bone loss and occurrence of fragility fractures in rheumatoid arthritis patients. Egyptian Rheumatologist 41(1):1-5

41. Kwok TCY, Law SW, Leung E, Choy D, Lam P, Leung $\mathrm{J}$ et al (2020) Hip fractures are preventable: a proposal for osteoporosis screening and fall prevention in older people. Hong Kong Med J 26(3):227-235

Publisher's Note Springer Nature remains neutral with regard to jurisdictional claims in published maps and institutional affiliations. 